\title{
The competitiveness of Brazilian tourist destinations
}

\section{Luiz Gustavo Medeiros Barbosa*}

Escola Brasileira de Administração Pública e de Empresas (EBAPE) da Fundação Getulio Vargas (FGV), Praia de Botafogo, $190-7^{\circ}$ andar, Rio de Janeiro, RJ, cep 22.250-900, Brasil Email: luiz.barbosa@fgv.br ${ }^{*}$ Corresponding author

\section{Carlyle Tadeu Falcão de Oliveira}

Programa de Pós-Graduação em Administração (PPGAd)

da Universidade Federal Fluminense (UFF),

Rua São Paulo, 30,

Campus do Valonguinho, Centro,

Niterói, RJ, CEP: 24020-150, Brasil

Email: carlyle.falcao@gmail.com

\begin{abstract}
This paper proposes a construct to measure the competitiveness of Brazilian tourist destinations and orient the actions of public and private tourism managers. The model of this study is based on a relevant literature review, a panel with specialists that have expertise in Brazilian tourism and field research. The investigation was carried out in 15 Brazilian tourist cities, representative of the socioeconomic diversity that characterises the heterogeneity of a developing country. The results of the study show the level of competitiveness of these 15 destinations according to the 13 dimensions proposed in the model, identifying the strong and weak points of local tourism. An assessment was carried out in detail that should serve to assist public managers in the strategic planning of these cities. As a complementary result, the study may be successfully replicated in other destinations, thus initiating a historical series for monitoring the competitiveness of Brazilian tourist destinations.
\end{abstract}

Keywords: competitiveness; tourism; Brazilian destinations.

Reference to this paper should be made as follows: Barbosa, Luiz G.M. and Oliveira, Carlyle T.F. (2015) 'The competitiveness of Brazilian tourist destinations', Int. J. Strategic Change Management, Vol. 6, No. 1, pp.21-34.

Biographical notes: Luiz Gustavo Medeiros Barbosa has a PhD from the University of Nottingham, UK, Master in Business Administration from FGV-EBAPE, Master in Tourism Management and Planning from Bournemouth University, UK, Bachelor of Economics from Fluminense Federal University. He is Project Coordinator of FGV Projects and Coordinator of several projects in the public and private sector. He is also Associate Editor of the Academic Journal of Observatory for Tourism Innovation. 
Carlyle Tadeu Falcão de Oliveira is Doctor in Administration from FGV-EBAPE, Master in Public Administration from FGV-EBAPE, Specialist in tourism from FGV, Specialist in Business Management from FGV, has degree in Civil Engineering from the Gama Filho University and degree in tourism from Rural Federal University of Rio de Janeiro. He is an Associate Editor of the Academic Journal of Observatory for Tourism Innovation, a Research Professor of Fluminense Federal University in the National Postdoctoral Program in Management.

\section{Introduction}

Although the phenomenon of competitiveness has been the subject of discussion and academic production in tourism, little has been discussed on the competitiveness of tourist destinations in developing countries and on the use of the concept for the management of tourist destinations.

Using the models of competitiveness in existing literature and analysing carefully the theories that underlie this phenomenon, this paper proposes a construct to measure the competitiveness of Brazilian tourist destinations and orient the actions of public and private tourism managers.

\section{Theoretical framework}

\subsection{Tourist destination competitiveness}

The literature on tourism presents a series of international experiences and studies concerning competitiveness in the tourism industry, such as Kozak and Rimmington (1999), Crouch and Ritchie (1999), Ritchie and Crouch (2000), Crouch (2007), Dwyer et al. (2000, 2001), Dwyer and Kim (2003), Gooroochurn and Sugiyarto (2004), MeliánGonzález and García-Falcón (2003), Enright and Newton (2004), Johns and Mattsson (2005), D'Hauteserre (2000), Zhang et al. (2011), Huang and Peng (2012), Wu et al. (2012), Dwyer et al. (2012), Risteski et al. (2012), Botti and Peypoch (2013), Croes and Kubickova (2013), Martínez et al. (2014).

Of those authors, four groups were considered as the most representative models by the number of citations in the literature on the subject: the Crouch and Ritchie model; the model of Dwyer and Kim; the Gooroochurn and Sugiyarto model and the world economic forum model (WEF).

Crouch and Ritchie (1999) have developed a conceptual model of competitiveness for destinations, based on four factors: qualification factors (or situational conditions); management of the destination; attractions and key resources; and support factors and resources.

The Dwyer and Kim (2003) model is composed of four dimensions that characterise the competitiveness of a destination, namely resources, destination management, situational conditions and demand conditions. The resource dimension comprises the characteristics of a destination that make it attractive to tourists to visit. The dimension of situational conditions encompasses all factors related to the impact of the external environment on the competitiveness of the destination. The dimension destination 
management is divided into industrial and governmental factors. The demand conditions dimension includes three basic elements of tourism demand: recognition (awareness), perception and preferences.

Gooroochurn and Sugiyarto (2004) have drawn up a model for the evaluation of the competitiveness of tourist destinations whose units of analysis were prices, economic openness, technological developments, structure, human development in tourism, social development, environment and human resources.

The WEF published a significant study on competitiveness in 2007, based on secondary data from various international organisms and a survey among leaders and executives present at the forum. Based on these figures, a ranking of competitiveness in tourism terms was drawn up, in which 130 countries were classified according to their level of competitiveness.

The competitiveness index developed by the WEF was based on models structured on 13 key elements: public policies and regulations, environmental legislation, safety, health and hygiene, priority given to the tourism sector, air transport infrastructure, ground transport infrastructure, tourism infrastructure, communications infrastructure, prices in the tourism sector, human resources, national perception of tourism, and natural and cultural resources. These elements were then grouped into three areas: regulatory, business environment and infrastructure, and natural, cultural and human resources.

In the last five years, the destination competitiveness literature has been enriched with other contributions.

Zhang et al. (2011) used the information entropy weight to obtain objectively the weight to the competitiveness factors, and apply the technique for order preference by similarity to ideal solution (TOPSIS) method to fully and objectively evaluate tourism destination competitiveness (TDC) in 16 Chinese cities. The TOPSIS is based on the fact that the ideal solution is composed of all the best indices, whereas the negative ideal solution is made up of all the worst attainable indices for solving a multiple criteria decision-making problem. Their 35 TDC indices included four tourism competitiveness aspects: resources endowment, tourism reception capacity, tourism industry strength and tourism support ability which is further divided into socio-economic support ability and eco-environment support ability.

Huang and Peng (2012) propose a novel approach to the TOPSIS using the Fuzzy Rasch model for determining how to obtain accurate fuzzy numbers for the criteria of competitiveness factors weights. The Rasch model is based on the concept that the probability of obtaining an item is a function of a latent trait or ability. They analysed the TDC of nine Asian countries using 6 criteria and 15 indices comprising availability of attractions, availability of service, affordability, positive market image, peace and stability and cultural links.

$\mathrm{Wu}$ et al. (2012) criticised the travel and tourism competitiveness index of the WEF suggesting that the equal importance given to all subindices and pillars limited the quality of information for policy-makers and inhibits better decision-making. The authors explored the causal relationships among the subindices and pillars affecting the overall rankings. They proposed a framework that integrates the data envelopment analysis for benchmarking analysis, the Bayesian network (BN) classifiers for cause-effect hypotheses development and the partial least squares path modelling for hypotheses testing. 
Dwyer et al. (2012) discussed tools for measuring destination performance with focus on importance performance analysis (IPA). The IPA model was employed to evaluate Slovenia's destination competitiveness as a function of both expectations concerning the significant attributes and judgements about their performance. The survey results provide information on those issues where Slovenia is considered to be performing best, and those areas that have the largest gaps between importance and performance. The results also provide empirical support for the inclusion of both industry level and destination attributes in studies of tourism competitiveness, suggesting that the importance of competitiveness attributes may vary across locations, depending on product mix and target market segments.

Risteski et al. (2013) presented three concepts for achieving destination competitiveness: development of sustainable destinations, destination management planning and implementation of integrated quality management. The authors considered that the quality of the tourist destination and the integrated management is linked to spatial planning and developmental issues. In this sense, spatial planning of a destination needs to incorporate sustainable tourism in a holistic and integrated approach.

Croes and Kubickova (2013) designed a tourism competitiveness index derived from satisfaction, productivity and quality of life. They claimed that a meaningful measurement of tourism competitiveness is performance (ex post concept) instead of efficiency (ex ante concept proposed by WEF T\&T Index). The authors measured the tourism competitiveness in six Central America countries using these three concepts and supported that successful destinations seem to correlate strongly with quality of life. The study provided indication of the success of the countries as related to their tourism policies and presented the main attributes of the leading destinations in those countries: strong real receipts per capita (high value of their product) and value added (tourism specialisation). These two attributes lead to quality of life level.

Botti and Peypoch (2013) implemented an multi-criteria decision analysis (MCDA) method ELECTRE I to four Hawaiian islands to analyse tourism destination relative competitiveness. The model is based on competitiveness factors cited in Ritchie and Crouch (2003). They showed that destination management, destination policy, planning and development, and qualifying and amplifying determinants are the foundation of TDC.

Martínez et al. (2014) introduced public policies and tourism marketing as determinant factors of destination competitiveness. They presented the results of a field study held in two tourist destinations recognised as World Heritage Sites by UNESCO. Their survey included 23 items that examined the following factors: public policies, foreign direct investment, tourism marketing, cultural resources, human resources, and quality and price of tourism services. The results show that the tourism competitiveness of the cities is the consequence of the relationships between the following factors: marketing, foreign direct investment, public policies, human resources and cultural resources. They concluded that actions and measures should be taken by government and private sector to have common guidelines and strategies to meet hosts' and visitors' needs.

According to those authors destination competitiveness can be measured by different methods. Therefore, the identification of key variables and indicators used in the models 
of competitiveness of tourist destinations, which already exists in the literature, may serve as a basis for the model proposed in this paper.

\subsection{Proposition for a new model for measurement of competitiveness in tourism destinations}

The development of any economic activity needs a proactive approach and the preparation of strategies that will ensure the achievement of the desired objectives. The establishment of such strategies requires profound understanding of the local reality - structures, economy, competitive advantages and fragility for its preparation process.

The adoption of a wide perspective, which may combine the main sub-sectors and the dimensions that compose the tourist activity, is considered the most appropriate one for the sector's development. Such perspective must include analyses and scenarios connected with infrastructure, tourist potential, economy, public policies and sustainability, with the purpose of measuring the current capability of the destination and the potential for development.

This model used other variables presented in the studies of competitiveness discussed herein, adapted to the local level (municipalities). One can observe the use of models of competitiveness by Ritchie and Crouch (2003), Dwyer and Kim (2003), Gooroochurn \& Sugiyarto (2004) and the $\operatorname{WEF}(2007,2009)$ for the variables presented in the proposed model: public health, energy and communication, financial facilities, urban development, transport and access, the vicinity of tourist source centres, tourist facilities, professional qualification, attractions, framework to support tourism, planning, promotion and marketing support, tourism research, business infrastructure, level of education, investment barriers, water supply and sanitation, environmental conservation units, cultural production and cultural-historical heritage. The identification of the key variables and indicators used in the prevailing models of the competitiveness of tourist destinations may serve as a basis for the model proposed in this study.

Considering the measuring of competitiveness, this model proposes to adapt and complement the competitiveness studies of the authors quoted to meet specific needs of destinations in developing countries. Among the main directions of the model, we can highlight

- the use of variables that are conducive to analysis of cities rather than countries, excluding micro-environment (business analysis)

- employment of factors and data sources that identify socioeconomic and structural deficiencies with greater precision in developing or underdeveloped destinations

- the adoption of competitiveness indicators based on the concepts of efficiency (ex ante) instead of performance indicators (ex post)

- the use of only the most objective indicators possible, avoiding those which purport to investigate values and/or perceptions of service users.

In the same way, as mentioned by Gooroochurn and Sugiyarto (2004) and WEF (2007, 2009), it was an option taken by this research to divide the elements that affect the competitiveness of a tourist destination in dimensions and variables (Figure 1). 
Figure 1 Macro-dimensions and dimensions (see online version for colours)

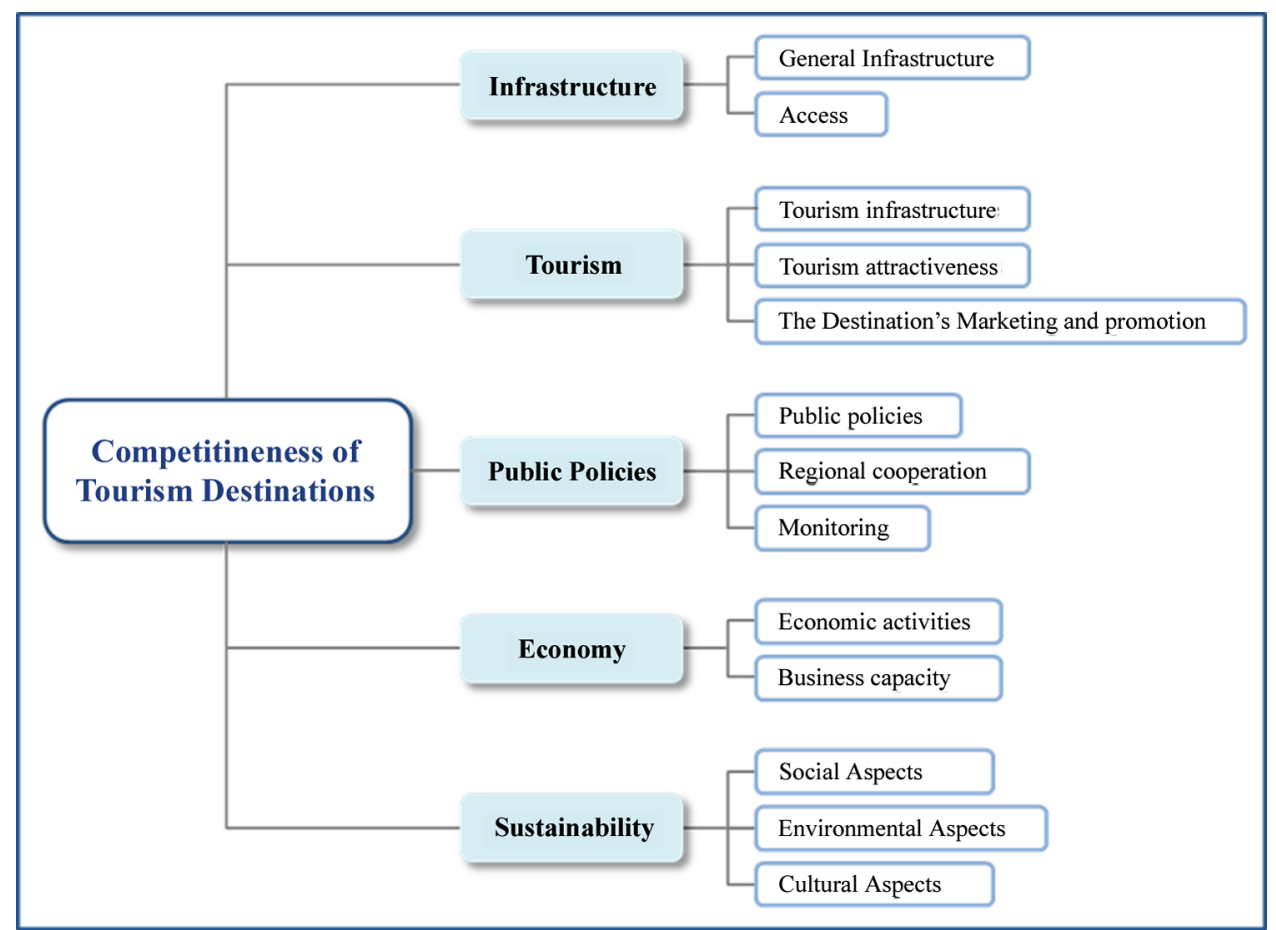

Source: Elaborated by the authors

\section{Methodology}

The analysis and the composition of the dimensions of this competitiveness model was based primarily on an extensive literature review in which the dimensions of competitiveness were extracted from and only later on were explored in detail by 13 tourism experts for the Brazilian case. Then an exploratory interview was proceeded to examine the relevance of the proposed conceptual model of destination competitiveness. In particular, a series of semi-structured interviews were conducted with 13 experts in Brazilian tourism studies. Those experts were divided into their areas of expertise according to each one of the 13 dimensions of the proposed model to explore its pertinent aspects of competitiveness, strategy and destination development in the Brazilian case.

A standardised questionnaire was applied with items measured in an objective way. The dimensions were expressed by variables. Such variables had objective questions presented according to a dichotomised answer (yes or no), multiple choices or with objective responses such as numbers and figures. The questionnaire contained 600 questions categorised into the primary data to be collected through interviews with respondents or by observation on site.

The definition of each macro-dimension and their respective dimensions, as well as the variables and questions that comprise them, allowed us to produce score criteria. This procedure was validated with experts in each one of the dimensions and, afterwards, 
validated in a meeting with representatives of the Ministry of Tourism and the private sector. Thus, for the competitiveness assessment of each tourist destination, a score, or weight, for each question, variable and dimension was attributed, taking into consideration the respective contributions to the global competitiveness index.

Each variable was defined to capture the overall comprehensiveness of the real meaning of the dimension it is part of. Thus, the score in each dimension was assessed as per the following calculation:

$$
\delta_{i}=\sum_{j=1}^{J}\left(\sum_{k=1}^{K}\left(x_{k j i}+\left(\left(\sum_{m=1}^{M} z_{m k j i}\right) I_{k j i}\right)\right) \omega_{k j i}^{\prime \prime}\right) \omega_{j i}^{\prime} \quad i=1,2, \ldots, 13
$$

where

$Z_{m}$ is the total score of subquestion $m(m=1,2, \ldots, M)$

$X_{k}$ is the total score of question $k(k=1,2, \ldots, K)$

$I=1$ if question $\mathrm{k}$ has subquestions; 0 , if the opposite takes place.

$\omega^{\prime}$ is weight attributed to variable $j$

$\omega$ " is weight attributed to question $k$.

This procedure allowed for identifying the relative positioning of each destination in each of the 13 dimensions. Per destination:

$$
\text { Final score }=\sum_{i=1}^{13}\left(\sum_{j=1}^{J}\left(\sum_{k=1}^{K}\left(x_{k j i}+\left(\left(\sum_{m=1}^{M} z_{m k j i}\right) I_{k j i}\right)\right) \omega_{k j i}^{\prime \prime}\right) \omega_{j i}^{\prime}\right) \omega_{i},
$$

where $\omega$ is weight attributed to dimension $i$.

The set of weights used in measurement of the dimensions was discussed and validated with a specialist panel. This panel comprised technicians from the Ministry of Tourism, the State Tourism Secretariats, Brazilian Service of Support for Micro and Small Enterprises (SEBRAE) representative and representatives of class and professionals entities in the sector as well as the academic researchers.

Data collection was performed between April and October 2009. In all destinations, the researchers relied on the constant presence of Municipal Tourism Secretariat personnel as well as of the respective state tourism body.

As interviewees, the representatives of other municipal secretariats, partner members of the city government, SEBRAE and the National Service of Commercial Learning also participated in the process of data obtainment. Likewise, professionals from educational institutions and representatives from hotels, restaurants, respective agencies and travel agency sectors were involved.

These 15 destinations were chosen for the following reasons:

- to cover all five geographical regions in Brazil

- $\quad$ to include different tourist attractions (priority tourism segments)

- to vary in terms of the size of economy and population 
- to have accessible local government managers

- to be considered by the Ministry of Tourism as priorities for tourism development in their respective regions.

In addition to the data collected in the field, the model comprised several other variables drawing upon the data available from official sources of recognised credit. This information served both to supplement the model database and to deal with variables that demanded treatment in a comparative framework, i.e. the need to be balanced in relation to size, public budgets or population in the destinations surveyed, for the purpose of comparability between them.

\section{Results and discussion}

The competitiveness index is presented as a scale of $0-100$ points. The overall result of destination competitiveness is shown in Table 1.

The overall result of the competitiveness index provided by the model highlights two groups of cities: state capital* (state government offices) and non-capitals. The first group achieved average competitiveness levels exceeding 70 points (with the exception of City VIII with 63.9 points), while the second group scored less than 61 points. This occurred because the model was constructed according to the principle of cause and effect and the 13 dimensions (with their respective weights) contributed to the total level of competitiveness of capital city destinations being superior to that of non-capital cities.

In this sense, the index numbers were higher in state capital cities in 12 of the 13 dimensions of competitiveness proposed by model: general infrastructure, access, tourist services and equipment, public policies, monitoring, local economy, business capacity, social aspects, environmental aspects and cultural aspects. Non-capital cities had higher index numbers only in the regional cooperation dimension. Considering the foregoing, there are visible differences in competitiveness in tourism across Brazil, indicating that the larger the degree of development in a destination, the more competitive it is. This is the case for the capital cities, where state government offices are located.

The question of the level of development and regional inequality is crucial to the design of a tourism competitiveness model for developing countries, since while in developed countries structural issues for tourism are consolidated and homogeneous in cities and territories, in developing countries, they vary from city to city.

For this reason, the model in this work proposes enhancing those dimensions that support tourist activity, such as access, infrastructure and tourist equipment and services. Some examples are the variables 'tourist signs', 'tourist protection services' and 'tourist information centres'. The first two were considered in the four models presented this work, while the third was only proposed in the model of competitiveness by Dwyer and $\operatorname{Kim}(2003)$.

Along this same line of reasoning is the question over the unit of analysis. Since one of the objectives of this paper was to propose a model that serves as a reference for managers to monitor the development of local tourism, it makes more sense that the analysis units are cities and not the country as a whole, as there are large gaps in the levels of competitiveness among Brazilian cities. 
Table 1 Consolidated results for the 15 tourist destinations

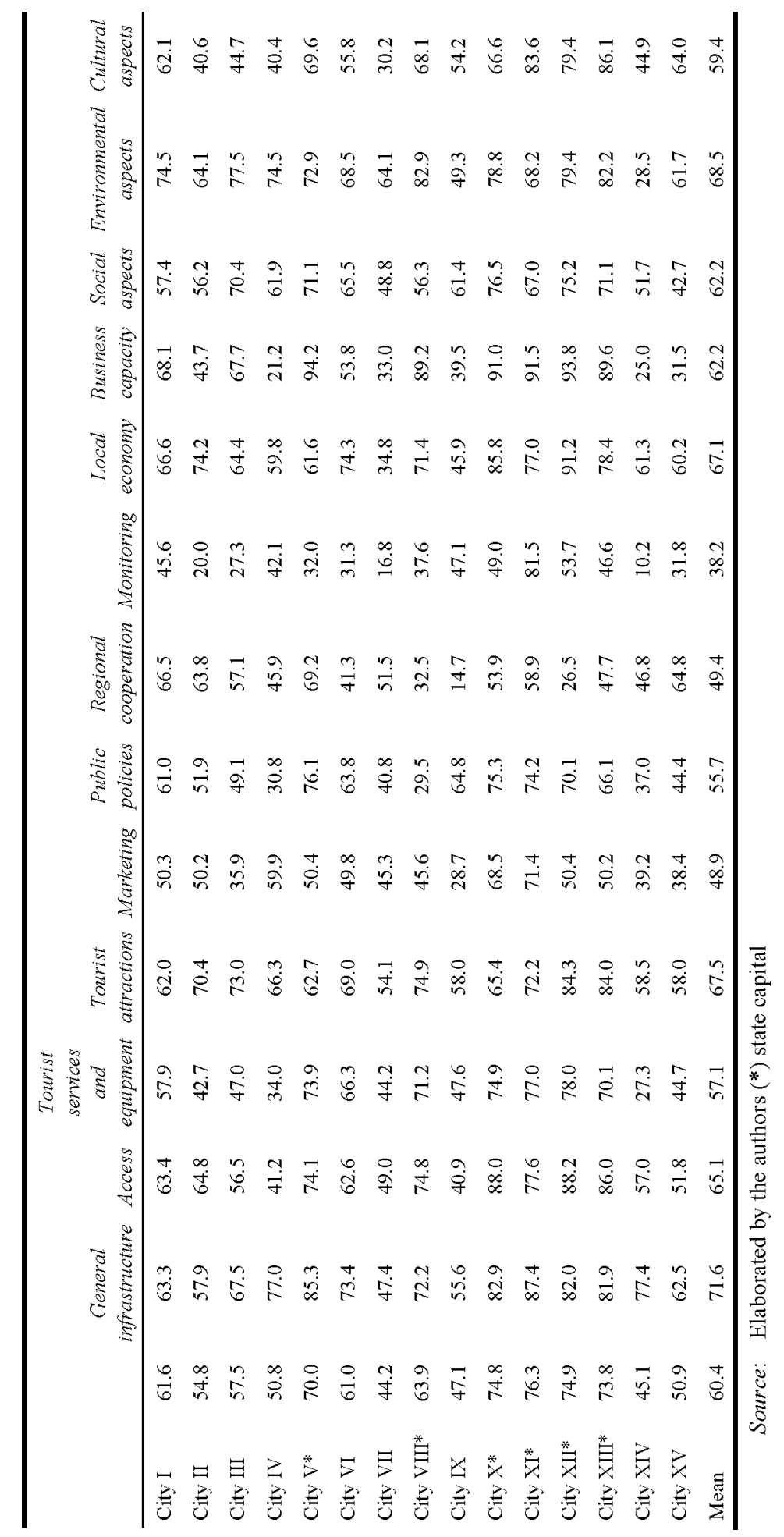


The question of measuring and monitoring competitiveness is also decisive for establishing a method of evaluation based on efficiency (ex ante concept). According to this assessment criterion, the identification of weaknesses (variables) in destination competitiveness is clearer, which would be difficult to determine if performance assessment was used (ex post concept) since very little information about tourism results is available in Brazilian destinations.

Cross-checking the results are an important issue that affects the sustainability of local tourism, for example. Cities with vibrant tourist attractions such as City XV (cultural segment), City XIV (rural segment), City IX (cultural segment) and City VII (sun and beach segment) presented reduced competitiveness rates on the attractions dimension (below 60 points) not only because of their poor infrastructure, but also because they do not meet the criteria of sustainability at a higher point of interest for tourist visits. Consequently, the model of this paper highlights the advantages of identifying factors that are prejudicial to tourism by means of three dimensions: social aspects, environmental aspects and cultural aspects (sustainability dimensions). By contrast, the other four models focus only on environmental sustainability.

The lowest index of the 13 dimensions is monitoring with 38.2 points. This score shows the low technical capacity and resources of local governments to establish indicators on tourism monitoring. Monitoring would be better conducted by the public sector or in partnership with research institutes seeking sustainable development in the destination. In most cases presented, it is not carried out at all.

In addition, the degree of cooperation between local governments and the central government and their respective state governments as well as public-private sector cooperation is low. This is pointed out by the public policy dimension indicator (55.66 points), which encompasses these variables in addition to local planning and local infrastructure to support tourism. The low results of this dimension, along with the monitoring and regional cooperation dimensions (49.4 points), denote the fragile capacity to work within networks, whether inter-destination (regional cooperation) or at levels of government (public policy).

Moreover, in relation to the unit of analysis, the proposed model in this research does not consider microeconomic or macroeconomic aspects, thus resembling more the models presented by Gooroochurn and Sugiyarto (2004), Ritchie and Crouch (2003) and WEF $(2007,2009)$, which favours the resource-based view from organisational studies to the detriment of the economic approach.

Accordingly, a destination is seen as an accumulation of resources represented by its dimensions and variables of competitiveness. By contrast, Dwyer and Kim's (2003) model considers macroeconomic and microeconomic factors besides those related to the destination's resources.

The model presented herein defines the phenomenon of competitiveness itself, moving away from those that verify the cause/consequence function. All models analysed made use of surveys and secondary data as sources of information, while this study collects data on site by means of observations and interviews and only refers to secondary data as a supplement.

A common result of deficiency (more evident in non-capital cities) in the management aspect of destinations can be observed: the fragility of governments and/or local leadership. This tends to become evident when you observe the vulnerability of the variables related to the normative and institutional apparatus of destinations, demonstrating clear bottlenecks for tourism competitiveness. 
One interesting point observed in the results is that the information acquired by the research is actually part of public managers' day-to-day work and may be used not just to compose this competitiveness evaluation but also as a reference for public policies: tourist protection programs, passenger terminals for the various modes of transport, incentives for the adoption of cleaner technologies, monitoring on the issue of accessibility for disabled persons, load capacity studies for attractions, conservation of attractions and surroundings, facilities and infrastructure at the attractions, destination marketing planning, qualified managers and own resources for the managing destinations, effectiveness of local government offices, the city's tourist sector planning, research and destination index systems, monitoring the impacts of tourism, barriers to entry of new tourism ventures, prevention of the sexual exploitation of children and adolescents, municipal funds for culture and the environment, updated environmental legislation and cultural incentive programs.

In view of the hindrances observed in the preceding paragraph, three interlinked lines of action for the improvement of the management of Brazilian tourist destinations can be defined: sustainability, public policies and governance.

Improving the sustainability of the destination is linked to the ability to monitor the impacts caused by tourist activities. There is a need for people and tools capable of developing studies of tourism. Furthermore, technicians and technologies may be obtained through partnerships with higher education institutions or agreements with other spheres of government as previously stated.

In addition to monitoring the results, it would be necessary for public policies to provide legal and institutional frameworks capable of providing cities with efficient legislation and enforcement for the protection of their natural resources, while favouring the practice of tourism in natural areas in a sustainable manner.

In the field of culture, incentives for cultural heritage preservation projects and the development of cultural tourism activities would serve to diversify and qualify the tourist offerings of destinations. Funds set up by law would support the budgets of those organisations responsible for cultural and environmental management.

Another function of public policies would be the elimination of barriers to the establishment of new businesses, tax incentives for new companies and lines of credit for entrepreneurs. Social dysfunctions can also be objects of public policies insofar as they are proactive, mitigating their causes.

The effectiveness of public policies for tourism competitiveness also depends on the performance of local governance along with management organisations in the destination, such as tourism boards. However, one of the weaknesses noted in this study is the inefficiency of such government offices. This gap may be one of the factors responsible for the lack of tourism planning in some destinations and, in many cities, the absence of a marketing plan. Not by chance, the outcome of competitiveness in the dimensions of marketing (48.95 points) and public policy (55.66 points) was, respectively, the second and the fourth lowest of all cities surveyed.

The growth of competitiveness of Brazilian tourism destinations has been one of the main objectives of Brazilian Tourism National Plan since 2007. In the period 2007-2011, the Ministry of Tourism adopted a methodology of research to identification of tourist destinations regions which could play an important inducer role of regional tourism development (Brazilian Ministry of Tourism, 2013).

The model presented in this paper has been served as the matrix that allows the assessment of competitiveness indices in strategic tourist regions to the improvement of 
the tourist experience. Since 2007, 65 tourist destinations were set in Brazil and this methodology has been used for assessing the competitiveness rate of each destination. As a consequence of that, there were investments to improve competitiveness on the areas pointed by the study.

Limited initially to these 65 destinations, the implementation of this study and the Brazilian Competitiveness Program shall be further territorially expanded as Brazilian Ministry of Tourism (2013) believes that by increasing the competitiveness of tourism in Brazil, it shall provide job creation and quality entrepreneurship.

\section{Conclusion}

The models of competitiveness present in the literature suffer limitations. Thus, this work sought to bridge some theoretical gaps in the Brazilian case. First, the choice of the city as the geographical unit of analysis provided greater detail on the factors affecting the competitiveness of local tourism. The city is also the smallest geographically and politically established area where tourists come in contact with the tourist product, making feasible actions of planning, organisation, direction and control.

Second, the 13 dimensions of competitiveness proposed by the model of this thesis, broken down into 61 variables and 600 questions/indicators, are based on the four models presented in this work, with some variations. The power of diagnostic accuracy and interpretation of local reality achieved was increased using a broader scope of conceptual models by Dwyer and Kim (2003) and Ritchie and Crouch (2003). The weighting system of dimensions and variables from the cause/effect models of Gooroochurn and Sugiyarto $(2004,2005)$ and $\operatorname{WEF}(2007,2009)$ was also incorporated. The sustainability of tourism was expanded to be composed of three specific dimensions (social, environmental and cultural), whose goal is to verify the degree of inclusion of local populations by means of tourist activities and their impacts on tourist attractions. Finally, specific variables for researching developing countries were included.

Third, this research was oriented by the concept of competitiveness. From this perspective, the experience perceived by the tourist was translated by indicators, whose data collection occurred by direct observations and interviews, and only complemented by secondary data. Thus, subjective information for the operationalisation of the competitiveness of Brazilian cities was quantified to capture competitiveness in an objective a manner as possible. Consequently, this study became innovative for prioritising primary data collection obtained from destinations to the detriment of secondary data and for combining qualitative and quantitative research.

Fourth, the particularities of Brazilian cities and large differences among them were two of the premises that motivated this work. The results of the research show great differences between capital cities and non-capitals, indicating that the competitiveness of destinations may be associated with their levels of development. Therefore, the measurement model for regions with large differences of development should provide a comprehensive analysis and the most direct contact possible with local reality. A model of this type would possess an extensive set of variables/indicators whose unit of analysis would be a relatively small field to obtain with acuity the phenomenon of competitiveness.

And finally, as managerial contributions, this model has been used by the Brazilian Ministry of Tourism to monitor 65 tourist destinations to point out errors in the 
city's environment from organisational, infrastructural, economic, social, cultural, environmental and political points of view, which may influence corrective actions to enhance destination competitiveness. This assessment will also assist public policy development and strategic planning, since the information generated has been analysed according to the dimensions and variables of the model. With the creation of a historical series, since 2007 , the results serve to track the evolution of the destination and the impacts caused by tourism in terms of sustainability.

In this sense, the present research has shown that the biggest deficiency in destinations is their incapacity to develop studies of tourism and to monitor its impacts because of a lack of specialist staff in destination management organisation (DMO). For this reason, a model that assesses local competitiveness in a comprehensive and detailed manner will serve as a management tool for local, state or central governments to assess, plan, direct and control cities to reach higher levels of competitiveness in tourism.

\section{References}

Botti, L. and Peypoch, N. (2013) 'Multi-criteria ELECTRE method and destination competitiveness', Tourism Management Perspectives, No. 6, pp.108-113.

Brazilian Ministry of Tourism (2013) Plano Nacional de Turismo 2013-2016: o turismo fazendo muito mais pelo Brasil, Ministério do Turismo, Brasília.

Croes, R. and Kubickova, M. (2013) 'From potential to ability to compete: towards a performancebased tourism competitiveness index', Journal of Destination Marketing \& Management, No. 2, pp.146-154.

Crouch, G.I. (2007) Modelling Destination Competitiveness: A Survey and Analysis of the Impact of Competitiveness Attributes, Technical Reports, Sustainable Tourism CRC, Australia, STCRC, pp.1-45.

Crouch, G.I. and Ritchie, B.J.R. (1999) 'Tourism, competitiveness and societal prosperity', Journal of Business Research, Vol. 44, No. 3, pp.137-152.

D'Hauteserre, A-M. (2000) 'Lessons in managed destination competitiveness: the case of Foxwoods Casino Resort', Tourism Management, Vol. 21, pp.23-32.

Dwyer, L. and Kim, C. (2003) 'Destination competitiveness: determinants and Indicators', Current Issues in Tourism, Vol. 6, No. 5, pp.369-414.

Dwyer, L., Cvelbar, L.K., Edwards, D. and Mihalic, T. (2012) 'Fashioning a destination tourism future: the case of Slovenia', Tourism Management, No. 33, pp.305-316.

Dwyer, L., Forsyth, P. and Rao, P. (2000) 'The price competitiveness of travel and tourism: a comparison of 19 destinations', Tourism Management, Vol. 21, No. 1, pp.9-22.

Dwyer, L., Forsyth, P. and Rao, P. (2001) The Price Competitiveness of Singapore as a Tourist Destination, Singapore Tourism Board, Singapore, May.

Enright, J.M. and Newton, J. (2004) 'Tourism destination competitiveness: a quantitative approach', Tourism Management, Vol. 25, pp.777-788.

Gooroochurn, N. and Sugiyarto, G. (2004) 'Measuring competitiveness', The Travel and Tourism Industry, Discussion Paper-TTRI, Nottingham University Business School, Nottingham. University of Nottingham, pp.1-22.

Gooroochurn, N. and Sugiyarto, G. (2005) 'Competitiveness indicators in the travel and tourism industry', Tourism Economics, Vol. 11, pp.25-43.

Huang, J.H. and Peng, K.H. (2012) 'Fuzzy Rasch model in TOPSIS: a new approach for generating fuzzy numbers to assess the competitiveness of the tourism industries in Asian countries', Tourism Management, Vol. 33, pp.456-465. 
Johns, N. and Mattsson, J. (2005) 'Destination development through entrepreneurship: a comparison of two cases', Tourism Management, Vol. 26. pp.605-616.

Kozak, M. and Rimmington, M. (1999) 'Measuring tourist destination competitiveness: conceptual considerations and empirical findings', Hospitality Management, Vol. 18, pp.273-283.

Martínez, R.M., Galván, M.O. and Lafuentec, A.M.G. (2014) 'Public policies and tourism marketing. An analysis of the competitiveness on tourism in Morelia, Mexico and Alcala de Henares, Spain', Procedia - Social and Behavioral Sciences, Vol. 148, pp.146-152.

Melián-González, A. and García-Falcón, J.M. (2003) 'Competitive potential of tourism in destinations', Annals of Tourism Research, Vol. 30, No. 3, pp.720-740.

Risteski, M., Kocevski, J. and Arnaudov, K. (2012) 'Spatial planning and sustainable tourism as basis for developing competitive tourist destinations', Procedia - Social and Behavioral Sciences, Vol. 44, pp.375-386.

Ritchie, J.R. and Crouch, G.I. (2003) The Competitive Destination: A Sustainable Tourism Perspective, CABI Publishing, Oxon, UK.

Ritchie, J.R.B. and Crouch, I.G. (2000) 'The competitive destination: a sustainability perspective', Tourism Management, Vol. 21, pp.1-7.

World Economic Forum (WEF) (2007) The Travel \& Tourism Competitiveness Report 2007: Furthering the Process of Economic Development, Blanke, J. and Chiesa, T. (Eds.), Genebra, Switzerland, pp.1-113.

World Economic Forum (WEF) (2009) The Travel \& Tourism Competitiveness Index 2009: Managing in a Time of Turbulence, Blanke, J. and Chiesa, T. (Eds.), Genebra, Switzerland, pp.1-107.

Wu, W-W., Lan, L.W., Lee, Y-T. (2012) 'Critiquing the World Economic Forum's concept of destination competitiveness: a further analysis', Tourism Management Perspectives, No. 4, pp.198-206.

Zhang, H., Gu, C-L., Gu, L-W. and Zhang, Y. (2011) 'The evaluation of tourism destination competitiveness by TOPSIS \& information entropy - a case in the Yangtze River Delta of China', Tourism Management, No. 32, pp.443-451. 